\title{
Incidence, predictors, and treatment options of critical limb ischaemia after use of collagen plug-based vascular closure devices
}

\author{
Omran Amer ${ }^{1}$, MD; Siri Binger ${ }^{1}$, BSc; Steffen Desch ${ }^{1,2}$, MD; Hans Michael Harnoss ${ }^{3}$, MD; \\ Gerhard Schuler ${ }^{1}, \mathrm{MD} ;$ Holger Thiele ${ }^{1,2}, \mathrm{MD}$; Ingo Eitel ${ }^{1,2 *}$, MD \\ 1. Department of Internal Medicine - Cardiology, University of Leipzig - Heart Center, Leipzig, Germany; 2. Medical Clinic II, \\ Department of Cardiology, Angiology, Intensive Care Medicine, University Heart Center Lübeck, Lübeck, Germany; \\ 3. Department of Vascular Surgery, University of Leipzig - Park Hospital, Leipzig, Germany
}

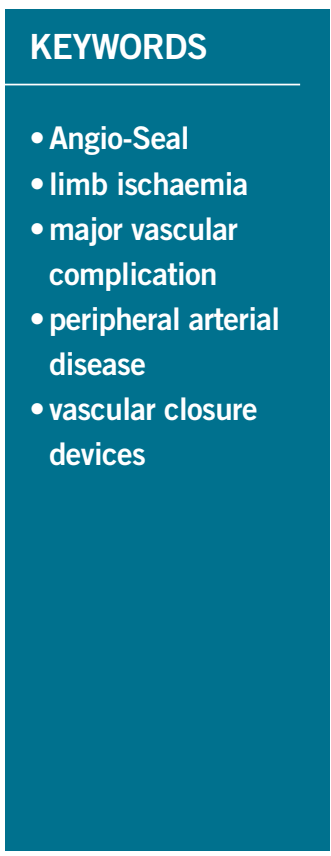

\begin{abstract}
Aims: Limited data are available on the frequency and predictors of vascular closure device (VCD) failure with subsequent vascular complications. The aim of this study was to investigate the incidence, clinical characteristics, and treatment options in patients with critical limb ischaemia (CLI) after use of a collagen plug-based VCD.
\end{abstract}

Methods and results: A high-volume, single-centre prospectively maintained database was retrospectively interrogated, and cases of collagen plug-based VCD-related CLI were identified between June 2006 and December 2013. CLI was defined as acute onset of rest pain after VCD application requiring endovascular or surgical treatment. Among 13,595 coronary procedures, 43 patients $(0.3 \%)$ were identified with an Angio-Seal-related CLI. In a multivariable logistic regression analysis, peripheral artery disease and renal insufficiency were identified as independent predictors for CLI after Angio-Seal application. Treatment was performed in 27 patients (63\%) by surgery and in 16 patients (37\%) with endovascular angioplasty.

Conclusions: CLI after use of a collagen plug-based VCD is rare. Peripheral artery disease was identified as an independent predictor of CLI. Interventional cardiologists should be aware of potentially high-risk patients and complications after use of a VCD to provide prompt and adequate therapy.

\footnotetext{
*Corresponding author: Medical Clinic II, Department of Cardiology, Angiology, Intensive Care Medicine, University Heart Center Lübeck, Ratzeburger Allee 160, 23538 Lübeck, Germany.E-mail: ingoeitel@gmx.de
} 


\section{Introduction}

The increasing number of endovascular procedures including approximately seven million cardiac catheterisations per year worldwide has resulted in the widespread use of arterial closure devices ${ }^{1}$. The aim of developing vascular closure devices (VCDs) was to achieve rapid haemostasis, a reduction in vascular complications, increasing patient comfort, a reduced time to ambulation, and a cost minimisation as compared to manual compression ${ }^{2,3}$. Currently, one of the most commonly used vascular closure systems is the Angio-SealTM (St. Jude Medical, St. Paul, MN, USA) which achieves direct femoral arterial haemostasis by anchoring a collagen plug to the anterior vascular wall through a sheath delivery system ${ }^{4}$.

Complications related to the use of VCDs include haematoma, bleeding, arteriovenous fistula, pseudoaneurysm, stenosis, thrombosis, embolisation, and infection. However, the most serious complication after application of collagen plug-based VCDs is limb ischaemia due to an intra-arterial deposition of collagen ${ }^{5}$. Femoral artery stenosis and occlusions leading to severe limb ischaemia or intermittent claudication following Angio-Seal deployment have been described in case reports ${ }^{1,4,5}$. However, there are no systematic data about the exact incidence and predictors of critical limb ischaemia (CLI) after Angio-Seal application. Moreover, the treatment of choice of VCD-related CLI remains unknown (endovascular or surgical management). The aim of the present study was to evaluate the incidence, predictors, and treatment options of CLI following Angio-Seal application.

\section{Methods PATIENTS}

A high-volume, single-centre prospectively maintained database was retrospectively interrogated, and collagen plug-based VCD (Angio-Seal) related CLI was identified between June 2006 and December 2013 at our institution. CLI was defined as acute onset of rest pain together with clinical signs of a cold pallor and pulseless leg requiring endovascular or surgical treatment. Percutaneous coronary catheterisation and/or intervention were performed according to standard clinical practice. The application of the VCD was performed according to the standard technique and the manufacturer's instructions ${ }^{6}$. However, femoral angiography was recommended but not routinely performed in all patients before application of the VCD.

Patients underwent immediate sheath control and were ambulated after two to four hours of bed rest after the coronary angiogram/procedure. Before discharge, evaluation of the access site was routinely performed and recorded for each patient. As a significant portion of patients was discharged the same day after the coronary angiogram and CLI may occur after the hospital discharge (e.g., presentation/re-admission in other hospital), we performed an additional telephone follow-up in 1,001 consecutive patients after Angio-Seal application to ensure that no major complication was missed (Figure 1). Follow-up was performed after a median of 18.5 months (IQR 13.8 to 20.8) after VCD application.

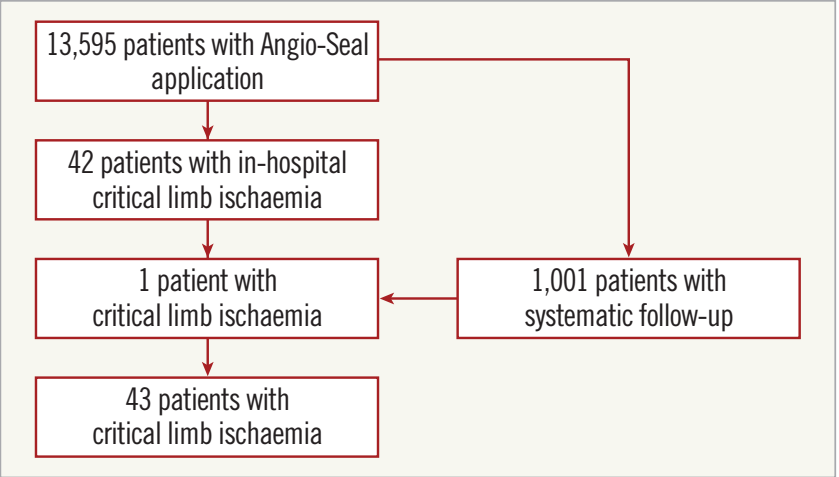

Figure 1. Study flow chart

\section{VASCULAR INVESTIGATIONS}

A clinical investigation of the puncture site was performed in all patients. Further vascular examination (colour-coded duplex sonography and/or arterial digital subtraction angiography) was performed in case of suspected complications (loss of peripherally palpable pulse, occurrence of claudication, or acute rest pain). Examination with duplex ultrasound imaging and angiography was performed according to standard clinical practice to evaluate the location and morphology of lesion and arterial haemodynamics?

\section{STATISTICAL ANALYSIS}

The collected data are reported in absolute and relative frequencies. Data for continuous variables are presented as median with 25th and 75th percentiles and categorical variables as frequencies and percentages. Differences between groups were assessed by the chi-square test for categorical variables and the t-test for continuous data. Univariate and stepwise multivariate Cox regression analyses were performed to identify predictors of major vascular complications. A p-value of $<0.05$ was defined as statistically significant. SPSS version 20.0 (IBM Corp., Armonk, NY, USA) was used for statistical analyses.

\section{Results \\ CLINICAL CHARACTERISTICS}

Among 13,595 coronary procedures with Angio-Seal application, 43 patients $(0.3 \%)$ developed CLI (Figure 1$)$. In the consecutive sample of 1,001 patients, one additional patient was identified as having a CLI. This patient was discharged the same day after coronary catheterisation from our tertiary care hospital and readmitted in another hospital because of severe leg pain with subsequent surgical treatment. The baseline characteristics of patients with CLI and patients without CLI are presented in Table 1. Patients with CLI had a significantly lower body mass index, higher incidence of peripheral artery disease, acute coronary syndrome, and chronic renal failure. These patient factors were also identified as predictors for the occurrence of CLI after Angio-Seal application in a univariable logistic regression analysis. Using stepwise 
Table 1. Patient characteristics.

\begin{tabular}{|c|c|c|c|c|c|}
\hline \multicolumn{2}{|c|}{ Variable } & Total study $n=13,595$ & No CLI $n=13,552$ & CLI $n=43$ & $p$-value \\
\hline \multicolumn{2}{|l|}{ Age, years } & $72(64-77)$ & $62(51-71)$ & $58(50-71)$ & 0.19 \\
\hline \multicolumn{2}{|c|}{ Age $\geq 80$ years, $n(\%)$} & 2,070/13,595 (16\%) & 1,995/13,595 (15\%) & $9 / 43(21 \%)$ & 0.36 \\
\hline \multicolumn{2}{|l|}{ Male sex, n (\%) } & $9,123 / 13,595$ (67\%) & 9,096/13,552 (67\%) & $27 / 43(63 \%)$ & 0.53 \\
\hline \multirow{4}{*}{$\begin{array}{l}\text { Cardiovascular } \\
\text { risk factors, } \\
\mathrm{n}(\%)\end{array}$} & Current smoking & $2,179 / 12,593$ (17\%) & $2,170 / 12,581(17 \%)$ & 9/43 (21\%) & 0.59 \\
\hline & Hypertension & $12,580 / 13,482(93 \%)$ & $12,539 / 13,441(93 \%)$ & $41 / 43(95 \%)$ & 0.64 \\
\hline & Hypercholesterolaemia & $8,779 / 13,482(65 \%)$ & $8,754 / 13,441(65 \%)$ & $25 / 43(58 \%)$ & 0.31 \\
\hline & Diabetes mellitus & $5,952 / 13,482(43 \%)$ & $5,834 / 13,441(43 \%)$ & $18 / 43(42 \%)$ & 0.83 \\
\hline \multicolumn{2}{|c|}{ Body mass index, $\mathrm{kg} / \mathrm{m}^{2}$} & $28(25-31)$ & $28(25-30)$ & $26(24-31)$ & 0.02 \\
\hline \multicolumn{2}{|l|}{ Obesity, n (\%) } & 4,990/13,482 (37\%) & $4,977 / 13,441(37 \%)$ & $13 / 43(30 \%)$ & 0.19 \\
\hline \multicolumn{2}{|c|}{ Atrial fibrillation, $\mathrm{n}(\%)$} & $3,792 / 13,482$ (28\%) & $3,780 / 13,441(28 \%)$ & $12 / 43(28 \%)$ & 0.98 \\
\hline \multicolumn{2}{|l|}{ PAD, n (\%) } & $1,209 / 13,482(9 \%)$ & $1,194 / 13,441(9 \%)$ & $15 / 43(35 \%)$ & $<0.001$ \\
\hline \multicolumn{2}{|c|}{ Intervention PAD, n (\%) } & $554 / 13,482(4 \%)$ & $547 / 13,441(4 \%)$ & $7 / 43(16 \%)$ & $<0.001$ \\
\hline \multicolumn{2}{|c|}{ Renal insufficiency, n (\%) } & $3,812 / 13,482(28 \%)$ & $3,791 / 13,441(28 \%)$ & $21 / 43(49 \%)$ & 0.002 \\
\hline \multicolumn{2}{|c|}{ Coronary artery disease, $\mathrm{n}(\%)$} & $10,611 / 13,595$ (78\%) & $10,576 / 13,552(78 \%)$ & $35 / 43(81 \%)$ & 0.58 \\
\hline \multicolumn{2}{|c|}{ Acute coronary syndrome, n (\%) } & 3,009/13,595 (22\%) & 2,993/13,552 (21\%) & $16 / 43(37 \%)$ & 0.03 \\
\hline \multicolumn{2}{|c|}{ Unstable angina } & $754 / 13,595(6 \%)$ & $750 / 13,552(6 \%)$ & $4 / 43(9 \%)$ & \\
\hline \multicolumn{2}{|l|}{ Non-STEMI } & $1,364 / 13,595(10 \%)$ & $1,355 / 13,552(9 \%)$ & 9/43 (21\%) & \\
\hline \multicolumn{2}{|l|}{ STEMI } & $891 / 13,595(7 \%)$ & $888 / 13,552(7 \%)$ & $3 / 43(7 \%)$ & \\
\hline \multirow[t]{2}{*}{ Radiation } & Radiation time, min & $3.8(1.5-7.2)$ & $3.7(1.5-7.3)$ & $5.5(2.2-7.1)$ & 0.77 \\
\hline & Radiation dose & $4,103(2,243-6,979)$ & $4,119(2,250-7,139)$ & $4,306(2,350-7,965)$ & 0.09 \\
\hline \multicolumn{2}{|c|}{ Sheath size, $n(\%)$} & & & & 0.12 \\
\hline \multicolumn{2}{|l|}{$5 \mathrm{Fr}$} & $3,337 / 13,595(25 \%)$ & $3,333 / 13,552(23 \%)$ & $4 / 43(9 \%)$ & \\
\hline \multicolumn{2}{|l|}{$6 \mathrm{Fr}$} & $9,323 / 13,595(69 \%)$ & $9,289 / 13,552(69 \%)$ & $34 / 43(80 \%)$ & \\
\hline \multicolumn{2}{|l|}{$>6 \mathrm{Fr}$} & $935 / 13,595(7 \%)$ & $930 / 13,552(6 \%)$ & $5 / 43(12 \%)$ & \\
\hline \multicolumn{2}{|c|}{ Total no. Angio-Seal applications: n (\%) } & & & & 0.78 \\
\hline \multicolumn{2}{|l|}{1} & $10,837 / 13,595(80 \%)$ & $10,804 / 13,552(80 \%)$ & $33 / 43(77 \%)$ & \\
\hline \multicolumn{2}{|l|}{2} & $1,943 / 13,595(14 \%)$ & $1,936 / 13,552(14 \%)$ & $7 / 43(16 \%)$ & \\
\hline \multicolumn{2}{|l|}{3} & $546 / 13,595$ (4\%) & $543 / 13,552(4 \%)$ & $3 / 43(17 \%)$ & \\
\hline \multicolumn{2}{|l|}{$>3$} & $269 / 13,595(2 \%)$ & $269 / 13,552(2 \%)$ & $0 / 43(0 \%)$ & \\
\hline \multicolumn{2}{|c|}{$\begin{array}{l}\text { Two Angio-Seal applications within } \\
3 \text { months, } \mathrm{n}(\%)\end{array}$} & $532 / 13,595$ (4\%) & $527 / 13,552(6 \%)$ & $5 / 43(12 \%)$ & 0.17 \\
\hline \multicolumn{6}{|c|}{$\begin{array}{l}\text { Continuous data are presented as median and interquartile range. Obesity was defined as BMI }>30 \mathrm{~kg} / \mathrm{m}^{2} \text {. Renal insufficiency was defined as creatinine } \\
\text { clearance }<90 \mathrm{ml} / \mathrm{min} \text {. Creatinine clearance was calculated according to the Cockcroft-Gault formula. PAD was defined on the basis of the patient } \\
\text { history, available charts and the results of the physical exam. CLI: critical limb ischaemia; Non-STEMI: Non-ST-elevation myocardial infarction; } \\
\text { PAD: peripheral artery disease: STEMI: ST-elevation myocardial infarction }\end{array}$} \\
\hline
\end{tabular}

multiple logistic regression analysis, only peripheral artery disease and renal insufficiency emerged as independent predictors of CLI after VCD application (Table 2).

\section{DIAGNOSTIC, TREATMENT AND CLINICAL OUTCOME}

All patients with clinical suspicion of limb ischaemia underwent colour-coded duplex sonography and angiography to confirm the diagnosis of an arterial occlusion.

Table 3 shows the occlusion sites and treatment of patients with CLI. In most patients the common femoral artery was occluded $(\mathrm{n}=35,81 \%)$ (Figure 2). The treatment choice (percutaneous approach versus surgical approach) was left to the discretion of the interventional angiologist. In 16 patients (37\%) endovascular
Table 2. Predictors of critical limb ischaemia in univariable and multivariable logistic regression analysis.

\begin{tabular}{|l|c|c|c|c|}
\hline \multirow{2}{*}{ Variable } & \multicolumn{2}{c|}{ Univariable } & \multicolumn{2}{c|}{ Stepwise multivariable } \\
\cline { 2 - 5 } & Hazard ratio (CI) & $\boldsymbol{p}$-value & Hazard ratio (CI) & $\boldsymbol{p}$-value \\
\hline Body mass index & $0.92(0.85-0.98)$ & 0.018 & - & - \\
\hline PAD & $6.58(3.37-12.85)$ & $<0.001$ & $5.08(2.54-10.17)$ & $<0.001$ \\
\hline Renal insufficiency & $1.72(1.13-2.64)$ & 0.012 & $2.38(1.26-4.51)$ & 0.023 \\
\hline Acute coronary syndrome & $1.31(1.00-1.74)$ & 0.05 & - & - \\
\hline $\begin{array}{l}\text { Renal insufficiency was defined as creatinine clearance <90 ml/min. Creatinine clearance } \\
\text { was calculated according to the Cockcroft-Gault formula; PAD was diagnosed on the basis } \\
\text { of the patient history, available charts and the results of the physical exam. Cl: confidence } \\
\text { interval; PAD: peripheral artery disease }\end{array}$ \\
\hline
\end{tabular}


Table 3. Vascular morphology and causes of vessel occlusion after Angio-Seal application.

\begin{tabular}{|c|c|c|c|}
\hline Possible causes & $\begin{array}{l}\text { Total } \\
n=43\end{array}$ & $\begin{array}{c}\text { Surgery } \\
n=27\end{array}$ & $\begin{array}{c}\text { PTA } \\
n=16\end{array}$ \\
\hline Superficial femoral artery occlusion & $5 / 43(9 \%)$ & $1 / 27(4 \%)$ & $4 / 16(25 \%)$ \\
\hline Femoral bifurcation occlusion & $2 / 43(5 \%)$ & $2 / 27(7 \%)$ & - \\
\hline Common femoral artery occlusion & $35 / 43(72 \%)$ & $23 / 27(85 \%)$ & $12 / 16(75 \%)$ \\
\hline Extensive sclerotic lesions & $21 / 43(49 \%)$ & $15 / 27(56 \%)$ & $6 / 16(38 \%)$ \\
\hline Dissection & $5 / 43(12 \%)$ & $4 / 27(15 \%)$ & $1 / 16(6 \%)$ \\
\hline Small vessel disease & $1 / 43(2 \%)$ & $1 / 27(4 \%)$ & - \\
\hline Distinctive vascular scarring & $3 / 43(7 \%)$ & $3 / 27(11 \%)$ & - \\
\hline Popliteal artery/below knee artery & $1 / 43(5 \%)$ & $1 / 27(4 \%)$ & - \\
\hline
\end{tabular}

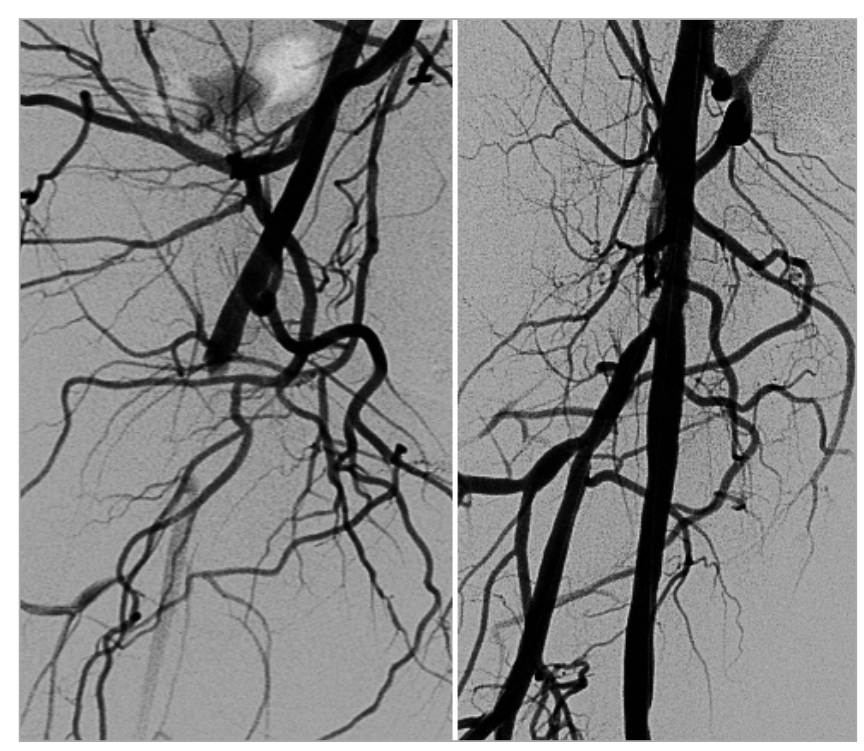

Figure 2. The angiogram shows an occlusion of the right common femoral artery after Angio-Seal application, which was successfully treated with thrombectomy and balloon angioplasty. treatment was performed, whereas in 27 patients $(63 \%)$ surgical treatment was necessary. In the endovascular treatment group, 15 patients $(94 \%)$ underwent balloon angioplasty, nine patients $(56 \%)$ stent implantation, eight patients (50\%) thrombectomy and three patients local fibrinolysis (19\%) (Figure 2, Figure 3). All patients were successfully treated by endovascular or surgical intervention.

Six patients (14\%) with VCD limb ischaemia died during their hospital stay. Of these, four patients were treated surgically and two patients by angioplasty. Most patients with fatal clinical outcome $(5 / 6,83 \%)$ were $\geq 80$ years and had a severely impaired left ventricular ejection fraction $\leq 35 \%(5 / 6,83 \%)$. The exact causes of death and clinical characteristics of patients who died after VCDassociated limb ischaemia are illustrated in Table 4.

\section{Discussion}

To the best of our knowledge, the current study is the first systematic investigation assessing the exact occurrence of CLI in a large, unselected cohort of patients undergoing coronary catheterisation with application of a collagen-based VCD. The main findings are: 1) CLI after use of a collagen plug-based VCD is rare; 2) peripheral artery disease and chronic renal failure were identified as independent predictors of VCD-related CLI; 3) VCDrelated CLI can be solved by either endovascular or surgical treatment. Consequently, interventional cardiologists should be aware of potential high-risk patients and complications after use of a VCD to provide prompt and adequate therapy.

\section{INCIDENCE AND CLINICAL RELEVANCE OF VCD COMPLICATIONS}

Arterial access-related vascular complications are among the most common adverse events after transfemoral angiography and PCI, and are associated with severe in-hospital morbidities and increased mortality rates. VCDs have emerged as an alternative to conventional mechanical compression after diagnostic

Table 4. Characteristics of patients and causes of death after VCD-associated limb ischaemia.

\begin{tabular}{|c|c|c|c|c|c|c|c|c|c|}
\hline Sex, age & $\begin{array}{l}\text { Coronary artery } \\
\text { disease }\end{array}$ & CABG & EF (\%) & PAD & ACS & PCI & $\begin{array}{c}\text { Renal } \\
\text { insufficiency }\end{array}$ & Treatment & Cause of death \\
\hline Male, 86 yrs & $\begin{array}{c}\text { Yes } \\
\text { 3-vessel disease }\end{array}$ & Yes & 28 & Yes & Yes & No & Yes & Surgical & Cardiogenic shock \\
\hline Female, 91 yrs & $\begin{array}{c}\text { Yes } \\
\text { 3-vessel disease }\end{array}$ & No & 30 & Yes & Yes & Yes & Yes & Surgical & Cardiogenic shock \\
\hline Female, 84 yrs & $\begin{array}{c}\text { Yes } \\
\text { 3-vessel disease }\end{array}$ & No & 35 & No & Yes & No & No & Surgical & Cardiogenic shock \\
\hline Male, 90 yrs & $\begin{array}{c}\text { Yes } \\
\text { 2-vessel disease }\end{array}$ & No & 40 & Yes & No & Yes & Yes & Surgical & Multiorgan failure \\
\hline Male, 62 yrs & $\begin{array}{c}\text { Yes } \\
1 \text {-vessel disease }\end{array}$ & No & 30 & Yes & No & Yes & No & $\begin{array}{l}\text { Angioplasty/ } \\
\text { Stent }\end{array}$ & Cardiogenic shock \\
\hline Male, 80 yrs & $\begin{array}{c}\text { Yes } \\
\text { 2-vessel disease }\end{array}$ & Yes & 32 & Yes & Yes & No & Yes & $\begin{array}{l}\text { Angioplasty/ } \\
\text { Stent }\end{array}$ & Multiorgan failure \\
\hline
\end{tabular}

Renal insufficiency was defined as creatinine clearance $<90 \mathrm{ml} / \mathrm{min}$. Creatinine clearance was calculated according to the Cockcroft-Gault formula. PAD was diagnosed on the basis of the patient history, available charts and the results of the physical exam. ACS: acute coronary syndrome; CABG: coronary artery bypass graft; EF: ejection fraction; PAD: peripheral artery disease; $\mathrm{PCl}$ : percutaneous coronary intervention 


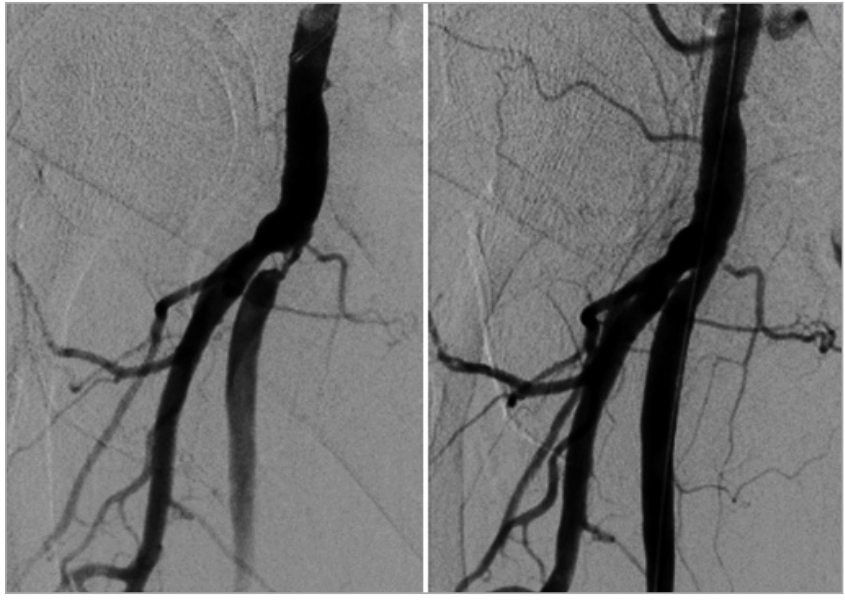

Figure 3. Subtotal occlusion of the proximal arteria femoralis superficialis caused by the Angio-Seal vascular closure device, successfully treated with balloon angioplasty.

angiography and PCI. These devices potentially reduce the time to haemostasis, facilitate patient mobilisation, decrease the length of hospital stay, and improve patient satisfaction ${ }^{8}$. Despite the widespread use of collagen plug-based VCDs (Angio-Seal) after cardiac catheterisations, limited data are available on the frequency and predictors of VCD-related vascular complications. Most published studies are retrospective, include only a small number of patients and have revealed inconclusive results ${ }^{1,9-15}$. Four metaanalyses, assessing the efficacy and safety of VCDs after diagnostic and interventional procedure ${ }^{16-19}$, suggested that the use of VCDs is associated with a significantly shorter time to haemostasis and cost-minimisation benefits; however, a benefit with respect to the prevention of vascular complications could not be demonstrated. Instead, the use of VCDs was associated with a somewhat increased risk of infection, lower limb ischaemia/arterial stenosis/ device entrapment in the artery, and need of vascular surgery for arterial complications. Consequently, further studies are needed to obtain more conclusive results, particularly in patients at high risk of femoral puncture-related complications.

More recent registries with more contemporary VCDs have shown a trend for reduction of vascular complications, although the risk of vascular complications was variable. The results of a recent large single-centre observational registry with, predominantly, use of the Angio-Seal VCD reported that the use of VCDs was associated with a $53 \%$ reduction in the overall vascular complication rate. The incidence of arterial occlusion in that study was $0.06 \%$. Other studies reported an even higher incidence of acute limb ischaemia after Angio-Seal application of between $0.2 \%$ and $0.5 \%{ }^{20,21}$. In line with these data, our largest study to date with $13,595 \mathrm{VCD}$ applications found a comparable rate of CLI with $0.3 \%$.

Femoral angiography is recommended by the manufacturer to help in deciding whether to apply a VCD or not. However, it is a matter of dispute whether femoral angiography should be routinely performed before VCD application in all patients undergoing coronary catheterisation. Although our data indicate that the occurrence of CLI after VCD without routinely performed femoral angiography is rather low, we cannot rule out that several cases with VCD-related CLI in our study could have been avoided by routine utilisation of femoral angiography in all patients. Therefore, at least in well-defined subsets (the elderly, patients with low BMI, patients with a known history of PAD) femoral angiography before applying a VCD should be mandatory.

Importantly, the sequelae of limb ischaemia after VCD application are clinically relevant, because of the need for surgical therapy in most cases. Patients with advanced age, left ventricular dysfunction, or the presence of multiple coexisting conditions are at high surgical risk. Indeed, 14\% of our patients with detected CLI died during their hospital stay.

\section{RISK FACTORS FOR VCD-ASSOCIATED COMPLICATIONS}

It is important to note that almost all randomised trials comparing the Angio-Seal device with manual compression excluded patients at high risk of puncture site complications, especially with the presence of peripheral artery disease, obesity, small common femoral artery, recent femoral artery puncture or inadequate arterial puncture $2,8,18,22-26$. Thus, it has not been fully elucidated if the presence of peripheral artery disease is a risk factor for the occurrence of major vascular complications after the use of Angio-Seal. However, a recent small publication investigated the utilisation of collagen-based VCD in 121 patients with severe peripheral artery disease. There was a trend towards a higher prevalence of vascular complications with higher stages of peripheral artery disease without reaching statistical significance ${ }^{27}$. In accordance with these data, our study clearly demonstrates that the presence of peripheral artery disease is a significant and independent predictor of CLI after Angio-Seal deployment. Potential mechanisms of VCDrelated CLI in patients with severe peripheral artery disease are: 1) placement of the anchor proximal to the puncture site in an arteriosclerotic plaque causing intravascular dislocation of the whole system; 2) incorrect position of the anchor due to an arteriosclerotic plaque in the puncture site with subsequent intra-arterial dislocation of collagen. Importantly, asymptomatic atherosclerosis of the common femoral artery is not described as a contraindication to Angio-Seal application.

Likewise, limited and conflicting data are available as to whether obesity is a potential risk factor of major vascular complications after VCD use ${ }^{28}$. In the present study, the BMI was significantly lower in patients with CLI after VCD use. The exact reasons for the increased risk in patients with low BMI remain unclear. A possible explanation is that such patients have naturally small arteries. Occlusion of the femoral artery after Angio-Seal application has been described in patients with small vessel diameter or disposition for vasospasm in previous studies ${ }^{29}$. Furthermore, in cachectic patients, collagen may protrude from the skin, and manipulation, pushing as well as tamping of the collagen, may result in intravascular dislocation. 
Another potential risk factor for limb ischaemia may be an Angio-Seal reapplication via the same femoral artery within the 90 days required for resorption of the device materials ${ }^{15}$. Our data support the currently published data that the application of AngioSeal can produce a reaction in the arterial wall with hyperplasia of the intima and proliferation of fibroblasts, despite the bioabsorbability of the device material ${ }^{30}$. Three of our patients $(11 \%)$ with Angio-Seal-related limb ischaemia had a distinct vascular scarring after repetitive application of Angio-Seal.

\section{TREATMENT OF CRITICAL LIMB ISCHAEMIA AFTER VCD APPLICATION}

Current knowledge of optimal treatment for major Angio-Sealrelated complications is limited. The decision between endovascular and surgical management is affected by the severity of symptoms and anatomical localisation of the occlusion. A specific interventional technique for major VCD-specific complications has not been established. Data on interventional therapy are limited to case reports and small series of follow-up ${ }^{31-35}$. The intention of the interventional treatment is a complete extraction of the entire occluding material using rotational thrombectomy and percutaneous transluminal angioplasty with or without stent implantation: this should be performed as quickly as possible to avoid apposition of additional thrombotic material requiring more difficult extraction. Published data support that endovascular treatment of Angio-Seal-related limb ischaemia is feasible and safe with excellent immediate results and long-term outcome ${ }^{31}$.

Likewise, successful surgical repair has been described in small uncontrolled series ${ }^{15,36-40}$. In our patient cohort, surgical therapy was performed if interventional therapy was not an option, especially in longer total occlusions or major thrombus formation. According to the mechanism of injury, removal of the Angio-Seal material and thrombectomy with or without patch angioplasty were performed. From our experience endovascular treatment is safe and should be preferred. However, if the anatomy of the occlusion site and characteristics are not suitable for interventional therapy, surgical removal of the Angio-Seal can be safely performed.

\section{Limitations}

The results of this study should be considered in the context of the following limitations. First, the study was conducted at a single centre in a non-randomised retrospective fashion. Second, a single type of VCD was used in this study to provide consistency in the device group, and divergent results with other types of VCD cannot be excluded. Third, our study has no control group, e.g., with manual compression. Thus, we cannot entirely rule out that a sizeable number of complications were more due to patient factors rather than caused by the VCD. Fourth, patients receiving diagnostic angiography as well as patients receiving PCI were included in the study. We are aware that this is a heterogeneous group of patients with different risk profiles, but we wanted to reflect everyday clinical practice in an all-comers population. Finally, we did not perform a routine femoral angiogram before VCD insertion, which may be important to understand which angiographic parameters can predict device success or failure.

\section{Conclusions}

The risk of CLI after use of a collagen plug-based VCD is low. Peripheral artery disease and chronic renal failure are independent predictors of CLI, and interventional cardiologists should be aware of this high-risk group.

\section{Impact on daily practice}

Critical limb ischaemia (CLI) after use of a collagen-based vascular closure device (VCD) is rare. However, interventional cardiologists should be aware of these potentially high-risk patients including patients with peripheral artery disease. In patients with VCD-related CLI, endovascular treatment is feasible and safe and should be preferred. However, if the anatomy of the occlusion site is not suitable for interventional therapy, surgical removal of the VCD can also be safely performed.

\section{Conflict of interest statement}

The authors have no conflicts of interest to declare.

\section{References}

1. Patel MR, Jneid H, Derdeyn CP, Klein LW, Levine GN, Lookstein RA, White CJ, Yeghiazarians Y, Rosenfield K; American Heart Association Diagnostic and Interventional Cardiac Catheterization Committee of the Council on Clinical Cardiology, Council on Cardiovascular Radiology and Intervention, Council on Peripheral Vascular Disease, Council on Cardiovascular Surgery and Anesthesia, and Stroke Council. Arteriotomy closure devices for cardiovascular procedures: a scientific statement from the American Heart Association. Circulation. 2010;122:1882-93.

2. Kussmaul WG 3rd, Buchbinder M, Whitlow PL, Aker UT, Heuser RR, King SB, Kent KM, Leon MB, Kolansky DM, Sandza JG Jr. Rapid arterial hemostasis and decreased access site complications after cardiac catheterization and angioplasty: results of a randomized trial of a novel hemostatic device. J Am Coll Cardiol. 1995;25:1685-92.

3. Resnic FS, Arora N, Matheny M, Reynolds MR. A cost-minimization analysis of the angio-seal vascular closure device following percutaneous coronary intervention. Am $J$ Cardiol. 2007;99:766-70.

4. Waksman R, King SB 3rd, Douglas JS, Shen Y, Ewing H, Mueller L, Ghazzal ZM, Weintraub WS. Predictors of groin complications after balloon and new-device coronary intervention. $\mathrm{Am}$ J Cardiol. 1995;75:886-9.

5. Chandrasekar B, Doucet S, Bilodeau L, Crepeau J, deGuise P, Gregoire J, Gallo R, Cote G, Bonan R, Joyal M, Gosselin G, Tanguay JF, Dyrda I, Bois M, Pasternac A. Complications of cardiac catheterization in the current era: a single-center experience. Catheter Cardiovasc Interv. 2001;52:289-95. 
6. Kensey KR. Puncture site hemostasis. J Invasive Cardiol. 1994;6:273-6.

7. Olin JW, Kaufman JA, Bluemke DA, Bonow RO, Gerhard MD, Jaff MR, Rubin GD, Hall W; American Heart Association. Atherosclerotic Vascular Disease Conference: Writing Group IV: imaging. Circulation. 2004;109:2626-33.

8. Amin FR, Yousufuddin M, Stables R, Shamim W, Al-Nasser F, Coats AJ, Clague J, Sigwart U. Femoral haemostasis after transcatheter therapeutic intervention: a prospective randomised study of the angio-seal device vs. the femostop device. Int $J$ Cardiol. 2000;76:235-40.

9. Looby S, Keeling AN, McErlean A, Given MF, Geoghegan T, Lee MJ. Efficacy and safety of the angioseal vascular closure device post antegrade puncture. Cardiovasc Intervent Radiol. 2008;31:558-62.

10. Mukhopadhyay K, Puckett MA, Roobottom CA. Efficacy and complications of Angioseal in antegrade puncture. Eur $J$ Radiol. 2005;56:409-12.

11. Biondi-Zoccai GG, Fusaro M, Tashani A, Mollichelli N, Medda M, De Giacobbi G, Inglese L. Angioseal use after antegrade femoral arteriotomy in patients undergoing percutaneous revascularization for critical limb ischemia: a case series. Int $J$ Cardiol. 2007;118:398-9.

12. Lupattelli T, Tannouri F, Garaci FG, Papa G, Pangos M, Somalvico F, Caravaggi C, Faglia E. Efficacy and safety of antegrade common femoral artery access closure using the Angio-Seal device: experience with 1889 interventions for critical limb ischemia in diabetic patients. $J$ Endovasc Ther. 2010;17:366-75.

13. Kapoor B, Panu A, Berscheid B. Angio-seal in antegrade endovascular interventions: technical success and complications in a 55-patient series. J Endovasc Ther. 2007;14:382-6.

14. Thalhammer C, Aschwanden M, Jeanneret C, Labs KH, Jäger KA. Symptomatic vascular complications after vascular closure device use following diagnostic and interventional catheterisation. Vasa. 2004;33:78-81.

15. Kirchhof C, Schickel S, Schmidt-Lucke C, SchmidtLucke JA. Local vascular complications after use of the hemostatic puncture closure device Angio-Seal. Vasa. 2002;31:101-6.

16. Nikolsky E, Mehran R, Halkin A, Aymong ED, Mintz GS, Lasic Z, Negoita M, Fahy M, Krieger S, Moussa I, Moses JW, Stone GW, Leon MB, Pocock SJ, Dangas G. Vascular complications associated with arteriotomy closure devices in patients undergoing percutaneous coronary procedures: a meta-analysis. $\mathrm{J} \mathrm{Am}$ Coll Cardiol. 2004;44:1200-9.

17. Vaitkus PT. A meta-analysis of percutaneous vascular closure devices after diagnostic catheterization and percutaneous coronary intervention. J Invasive Cardiol. 2004;16:243-6.

18. Biancari F, D’Andrea V, Di Marco C, Savino G, Tiozzo V, Catania A. Meta-analysis of randomized trials on the efficacy of vascular closure devices after diagnostic angiography and angioplasty. Am Heart J. 2010;159:518-31.

19. Koreny M, Riedmüller E, Nikfardjam M, Siostrzonek P, Müllner M. Arterial puncture closing devices compared with standard manual compression after cardiac catheterization: systematic review and meta-analysis. JAMA. 2004;291:350-7.

20. Klocker J, Gratl A, Chemelli A, Moes N, Goebel G, Fraedrich G. Influence of use of a vascular closure device on incidence and surgical management of access site complications after percutaneous interventions. Eur J Vasc Endovasc Surg. 2011;42:230-5.

21. Eggebrecht H, Haude M, Woertgen U, Schmermund A, von Birgelen C, Naber C, Baumgart D, Kaiser C, Oldenburg O, Bartel T, Kroeger K, Erbel R. Systematic use of a collagen-based vascular closure device immediately after cardiac catheterization procedures in 1,317 consecutive patients. Catheter Cardiovasc Interv. 2002;57:486-95.

22. Chevalier B, Lancelin B, Koning R, Henry M, Gommeaux A, Pilliere R, Elbaz M, Lefevre T, Boughalem K, Marco J, Dupouy P; HEMOSTASE Trial Investigators. Effect of a closure device on complication rates in high-local-risk patients: results of a randomized multicenter trial. Catheter Cardiovasc Interv. 2003;58:285-91.

23. Deuling JH, Vermeulen RP, Anthonio RA, van den Heuvel AF, Jaarsma T, Jessurun G, de Smet BJ, Tan ES, Zijlstra F. Closure of the femoral artery after cardiac catheterization: a comparison of Angio-Seal, StarClose, and manual compression. Catheter Cardiovasc Interv. 2008;71:518-23.

24. Juergens CP, Leung DY, Crozier JA, Wong AM, Robinson JT, Lo S, Kachwalla H, Hopkins AP. Patient tolerance and resource utilization associated with an arterial closure versus an external compression device after percutaneous coronary intervention. Catheter Cardiovasc Interv. 2004;63:166-70.

25. Martin JL, Pratsos A, Magargee E, Mayhew K, Pensyl C, Nunn M, Day F, Shapiro T. A randomized trial comparing compression, Perclose, Proglide and Angio-Seal VIP for arterial closure following percutaneous coronary intervention: the CAP trial. Catheter Cardiovasc Interv. 2008;71:1-5.

26. Reddy BK, Brewster PS, Walsh T, Burket MW, Thomas WJ, Cooper CJ. Randomized comparison of rapid ambulation using radial, 4 French femoral access, or femoral access with AngioSeal closure. Catheter Cardiovasc Interv. 2004;62:143-9.

27. Kara K, Mahabadi AA, Berg MH, Kahlert P, Longwitz D, Erbel R, Bollow M. Utilization of collagen-based vascular closure devices in patients with severe peripheral artery disease. J Invasive Cardiol. 2013;25:19-22.

28. Minko P, Katoh M, Gräber S, Buecker A. Obesity: an independent risk factor for insufficient hemostasis using the AngioSeal vascular closure device after antegrade punctures. Cardiovasc Intervent Radiol. 2012;35:775-8.

29. Silber S, Schön N, Seidel N, Heiss-Bogner J. [Accidental occlusion of the common femoral artery after Angio-Sealapplication]. Z Kardiol. 1998;87:51-5.

30. Van den Broek T, Liqui Lung PF, Suttorp MJ, Eefting FD, Schipper ME, Vink A. Arterial occlusion after repetitive angioseal device closure. Vasc Endovascular Surg. 2007;41:346-7.

31. Thalhammer C, Joerg GR, Roffi M, Husmann M, Pfammatter T, Amann-Vesti BR. Endovascular treatment of 
Angio-Seal-related limb ischemia--primary results and long-term follow-up. Catheter Cardiovasc Interv. 2010;75:823-7.

32. Goyen M, Manz S, Kröger K, Massalha K, Haude M, Rudofsky G. Interventional therapy of vascular complications caused by the hemostatic puncture closure device angio-seal. Catheter Cardiovasc Interv. 2000;49:142-7.

33. Stein BC, Teirstein PS. Nonsurgical removal of angio-seal device after intra-arterial deposition of collagen plug. Catheter Cardiovasc Interv. 2000;50:340-2.

34. Steinkamp HJ, Werk M, Beck A, Teichgräber U, Haufe M, Felix R. Excimer laser-assisted recanalisation of femoral arterial stenosis or occlusion caused by the use of Angio-Seal. Eur Radiol. 2001;11:1364-70.

35. Lee JH, Biring TS, Gimelli G. Treatment of an Angio-Seal related vascular complication using the SilverHawk plaque excision system: a case report. Catheter Cardiovasc Interv. 2007;69:141-5.

36. Dregelid E, Jensen G, Daryapeyma A. Complications associated with the Angio-Seal arterial puncture closing device: intra-arterial deployment and occlusion by dissected plaque. $J$ Vasc Surg. 2006;44:1357-9.

37. Castelli P, Caronno R, Piffaretti G, Tozzi M, Lomazzi C. Incidence of vascular injuries after use of the Angio-Seal closure device following endovascular procedures in a single center. World J Surg. 2006;30:280-4.

38. Biancari F, Ylönen K, Mosorin M, Lepojärvi M, Juvonen T. Lower limb ischemic complications after the use of arterial puncture closure devices. Eur J Vasc Endovasc Surg. 2006;32: 504-5.

39. Pontón A, Negueruela CP, Bernal JM, García I, Arnáiz E, Solórzano LD, Revuelta JM. Surgical treatment of arterial ischemia associated with the use of the angioseal vascular closure device. Vasa. 2009;38:334-7.

40. Siani A, Accrocca F, Gabrielli R, Antonelli R, Giordano AG, Ambrogi C, Marcucci G. Management of acute lower limb ischemia associated with the Angio-Seal arterial puncture closing device. Interact Cardiovasc Thorac Surg. 2011;12:400-3. 